\title{
Formulation and Optimization of Eudragit RS PO-Tenofovir Nanocarriers Using Box-Behnken Experimental Design
}

\author{
Kefilwe Matlhola, ${ }^{1}$ Lebogang Katata-Seru, ${ }^{1}$ Lesego Tshweu, ${ }^{2}$ Indra Bahadur, \\ Gertrude Makgatho, ${ }^{3}$ and Mohammed Balogun ${ }^{2}$ \\ ${ }^{1}$ Chemistry Department, Faculty of Agriculture, Science and Technology, North West University, Mafikeng Campus, \\ Private Bag X2046, Mmabatho 2735, South Africa \\ ${ }^{2}$ Council for Scientific and Industrial Research, Materials Science and Manufacturing, Polymers and Composites, \\ P.O. Box 395, Meiring Naude Road, Brummeria, Pretoria 0001, South Africa \\ ${ }^{3}$ Council for Scientific and Industrial Research, Materials Science and Manufacturing, DST/CSIR National Centre for \\ Nanostructured Materials, P.O. Box 395, Meiring Naude Road, Brummeria, Pretoria 0001, South Africa \\ Correspondence should be addressed to Lebogang Katata-Seru; lebzakate@yahoo.com
}

Received 22 May 2015; Revised 11 September 2015; Accepted 14 September 2015

Academic Editor: Tapan Desai

Copyright ( 2015 Kefilwe Matlhola et al. This is an open access article distributed under the Creative Commons Attribution License, which permits unrestricted use, distribution, and reproduction in any medium, provided the original work is properly cited.

The objective of present study was to develop an optimized polymeric nanoparticle system for the antiretroviral drug tenofovir. A modified nanoprecipitation method was used to prepare Eudragit RS PO nanoparticles of the drug. The effect of amount of polymer, surfactant concentration, and sonication time on particle size, particle distribution, encapsulation efficiency (EE), and zeta potential were assessed and optimized utilizing a three-factor, three-level Box-Behnken Design (BBD) of experiment. Fifteen formulations of nanoparticles were prepared as per BBD and evaluated for particle size, polydispersity index (PDI), EE, and zeta potential. The results showed that the measured mean particle sizes were in the range of 233 to $499 \mathrm{~nm}$, PDI ranged from 0.094 to 0.153 , average zeta potential ranged from -19.9 to $-45.8 \mathrm{mV}$, and EE ranged between 98 and $99 \%$. The optimized formulation was characterized for in vitro drug release and structural characterization. The mean particle size of this formulation was $233 \mathrm{~nm}$ with a PDI of 0.0107 . It had a high EE of $98 \%$ and average zeta potential of $-35 \mathrm{mV}$, an indication of particle stability. The FTIR showed some noncovalent interactions between the drug and polymer but a sustained release was observed in vitro for up to 80 hours.

\section{Introduction}

Tenofovir is one of the first-line drugs used in the treatment of the human immunodeficiency virus (HIV) infected adults. It is a potent inhibitor of the virus nucleotide reverse transcriptase and was approved for clinical use in 2001 [1]. Its relatively low toxicity, long plasma half-life of 17 hours, and convenient dosing of $300 \mathrm{mg}$ per day has made it favoured in HIV/AIDS-burdened countries like South Africa [2]. It is also an important component of the fixed dose antiretroviral combinations Truvada, Atripla, and Complera [3]. However, tenofovir suffers from nephrotoxicity, high aqueous solubility and is characterized by low gastrointestinal membrane penetration, which lowers its bioavailability to $25 \%$ [4]. Therefore, to maintain the oral delivery route, formulating the drug into polymeric nanoparticles is essential for improving the bioavailability.

Nanoparticles present significant advantages over conventional free drug dosing $[5,6]$. There is minimal drug loss during transit through the gastrointestinal tract while the particles evade degradation in the acidic environment of the stomach. Their size and surface properties allow for uptake, without disrupting the particles' integrity, by $\mathrm{M}$ cells in the Peyer's patches of the small intestine [7]. The lymphoid tissue associated with these patches facilitates distribution of the nanoparticles through the systemic circulations. While in the systemic circulation the nanoparticles extend the halflife of the drug and release it in a sustained manner. The resultant benefit is a reduction of therapeutic dose, increased bioavailability, and limitation of toxic side-effects. 
The selection of a polymer for encapsulation is informed by several factors including the desired nanoparticle design and its biocompatibility [8]. Eudragit polymers are commercially available synthetic polymers used in drug delivery. They are copolymers of acrylic and methacrylic esters compatible with oral drug administration [9]. Eudragit RS PO is a derivative with quaternary ammonium functional group [10]. It is insoluble at the physiological $\mathrm{pH}$ but the cationic charge facilitates rapid permeation through the intestinal mucosa [10]. This means that the drug payload can be transported by diffusion. Eudragit RS PO is used in the pharmaceutical industry as a film-coating agent for tablets and capsule [11]. It has also been used in the preparations of timecontrolled drug delivery formulations [12]. Tenofovir was encapsulated in Eudragit RS PO in this study intended for oral administration since most studies are based on the prevention of HIV transmission [13].

The most important characteristics of drug-bearing nanoparticles are size, encapsulation efficiency (EE), zeta potential, and drug release [14]. Various formulation and process variables such as amount of polymer, concentration of surfactant, amount of drug, stirring speed, stirring time, and temperature play a key role in determining the final physical and mechanical characteristics of nanoparticles. These parameters are often screened and optimized using highly automated statistical tools and design of experiment. Box-Behnken Design (BBD) is an experimental design of response surface methodology. It is one of the most popular experimental designs which is used for the development and optimization of drug delivery systems [8] and it offers the advantage of exploring more than three formulation variables to minimize the number of wet experiments to be carried out [15]. Apart from this, BBD was chosen in this study because it is a more cost-effective technique than other similar experimental designs like central composite design, D-optimal design, and Latin square design which require 20 runs and 5 levels of the factor [13]. It also does not contain any points at the corners, which helps to avoid unreasonable results [16].

More than $50 \%$ of the nanoparticles reported in the literature are prepared by nanoprecipitation [17]. It is also known as solvent displacement or interfacial deposition method and was developed about 40 years ago [18]. Compared to other methods like emulsion [19], desolvation [20], salting out, and supercritical fluid technology it involves an economy of energy and steps and does not require specialized equipment. Particles synthesized by nanoprecipitation are typically of the size $200 \mathrm{~nm}$ [21]. In this project we used a modified nanoprecipitation method to encapsulate tenofovir.

\section{Materials and Methods}

2.1. Materials. Polyvinyl alcohol (PVA) (molecular weight 13-23 kDa, 87-89\% hydrolyzed), sodium dodecyl sulphate (SDS), Pluronic F127, Poloxamer 188, and acetone were purchased from Sigma-Aldrich (South Africa). Tenofovir was purchased from DB Fine Chemicals (South Africa). Eudragit RS PO (average molecular weight, $35 \mathrm{kDa}$ ) was received as a gift from Evonik (South Africa). All other chemicals used were of analytical grade and purchased from Sigma-Aldrich (South Africa).

2.2. Solubility Studies. Solubility experiments were carried out by adding excess amount of tenofovir $(134 \mathrm{mg})$ in $5 \mathrm{~mL}$ of surfactants (PVA, SDS, Poloxamer 188, and Pluronic F127) in stoppered vials and agitated on a shaker at $100 \mathrm{rpm}$ for 24 hours at room temperature. The solution was filtered through a $0.45 \mu \mathrm{m}$ membrane filter and the concentration of the drug was determined using UV/Vis spectrophotometer at $260 \mathrm{~nm}$ (Perkin Elmer, Lambda 35, Singapore).

2.3. Experimental Design and Analysis. The BBD (three factors, Quantum XL, Sigma) was used to study the influence of formulation parameters in optimizing the preparation of nanoparticles. Effects of three independent parameters, namely, ratio of a polymer to a drug $\left(X_{1}\right)$, concentration of surfactant $\left(X_{2}\right)$, and sonication time $\left(X_{3}\right)$ on average particles size $\left(Y_{1}\right)$, particle size distribution (expressed as polydispersity index, PDI) $\left(Y_{2}\right)$, encapsulation efficiency (EE) $\left(Y_{3}\right)$, and zeta potential $\left(Y_{4}\right)$ were studied. They were selected at their low, medium, and high levels with replicated centre points as shown in Table 1. The completed design consisted of 15 experimental runs, which were done in triplicate.

Analysis of variation (ANOVA) helps to identify the significant independent factors that affect the responses [22] and the fitness of the model. It was applied to determine the significance and the magnitude of the effects of the main variable and their interactions by applying probability value ( $p$ value). The fitness of the model was checked by coefficient of determination $\left(R^{2}\right)$ and signal to noise ( $F$-test). A nonlinear quadratic model correlating the relationship between the independent and dependent variables were generated and shown in

$$
\begin{aligned}
Y= & b_{0}+b_{1} X_{1}+b_{2} X_{1}+b_{3} X_{3}+b_{12} X_{1} X_{2}+b_{13} X_{1} X_{3} \\
& +b_{23} X_{2} X_{3}+X_{3}^{2},
\end{aligned}
$$

where $Y$ is the dependent variable, $b_{0}$ is the intercept, $b_{1}$ to $b_{23}$ are the regression coefficients, and $X_{1}, X_{2}$, and $X_{3}$ are the independent variables. To graphically demonstrate the influence of each factor on the response, the surface plots for each response were generated results using BBD [23].

\subsection{Preparation of Nanoparticles. Tenofovir nanoparticles} were prepared using modified nanoprecipitation method [24] in accordance with BBD (Table 2). Fifteen different amounts of Eudragit RS PO were dissolved in acetone $(3 \mathrm{~mL})$ and diluted with distilled water $(2 \mathrm{~mL})$ under sonication for $5 \mathrm{~min}$. The prepared solutions were added into $10 \mathrm{~mL}$ of the aqueous phases containing $50 \mathrm{mg}$ of tenofovir and different percentages of SDS, which were previously sonicated for 10 minutes. Subsequently, nanoparticles were formed which turned the aqueous phase slightly milky with bluish opalescence. However, the mixtures were continued to be sonicated at different time frames and were left to stir overnight to aid size reduction and to evaporate solvent present. 
TABLE 1: BBD experimental parameters and levels for preparation of nanoparticles.

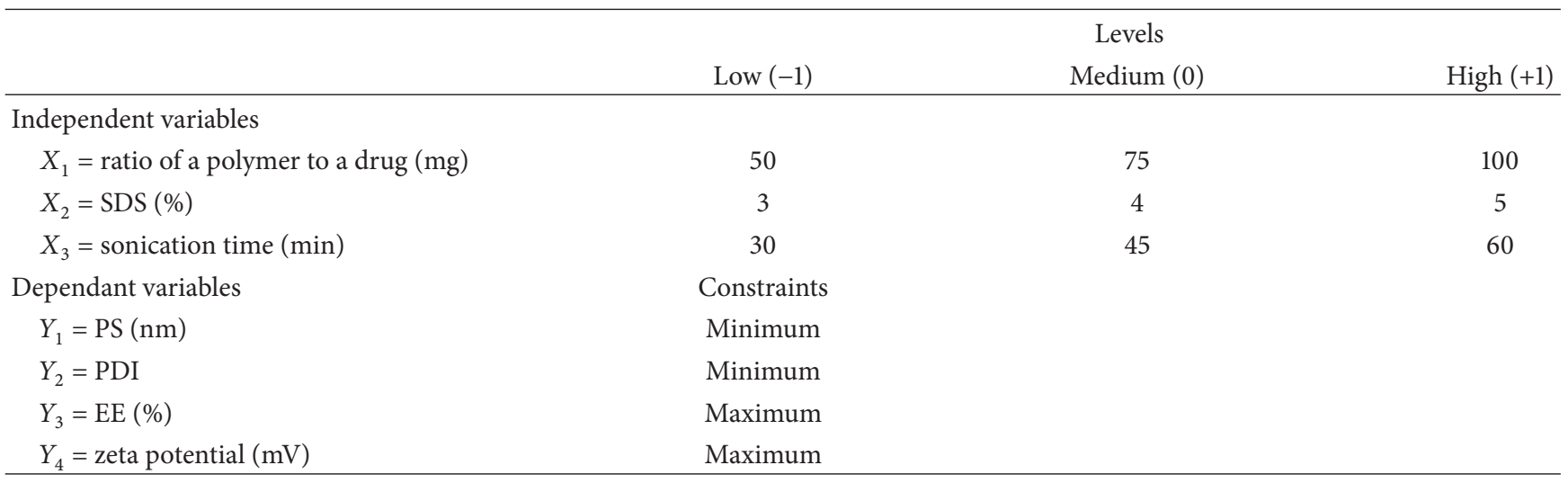

TABLE 2: BBD experimental parameters and levels for preparation of nanoparticles.

\begin{tabular}{lccc}
\hline Run & $\begin{array}{c}X_{1} \\
\text { Ratio of a } \\
\text { polymer to a } \\
\text { drug }(\mathrm{mg})\end{array}$ & $\begin{array}{c}X_{2} \\
\text { Concentration } \\
\text { of a surfactant } \\
(\% \text { SDS })\end{array}$ & $\begin{array}{c}X_{3} \\
\text { Sonication time } \\
(\mathrm{min})\end{array}$ \\
\hline 1 & 50 & 3 & 45 \\
2 & 50 & 5 & 45 \\
3 & 100 & 3 & 45 \\
4 & 100 & 5 & 45 \\
5 & 50 & 4 & 30 \\
6 & 50 & 4 & 60 \\
7 & 100 & 4 & 30 \\
8 & 100 & 4 & 60 \\
9 & 75 & 3 & 30 \\
10 & 75 & 3 & 60 \\
11 & 75 & 5 & 30 \\
12 & 75 & 5 & 60 \\
13 & 75 & 4 & 45 \\
14 & 75 & 4 & 45 \\
15 & 75 & 4 & 45 \\
\hline
\end{tabular}

2.5. Particle Size, Particle Size Distribution, and Zeta Potential. The mean particle size, particle size distribution (PDI), and zeta potential of nanoparticles were determined using Malvern Zetasizer Nano ZS (Malvern Instruments, United Kingdom). Each sample was measured in triplicate. The results are expressed as mean standard deviation (SD).

2.6. Encapsulation Efficiency and Drug Loading of Nanoparticles. The encapsulation efficiency and drug loading of nanoparticles were determined by UV/Vis spectrophotometry. The prepared samples were centrifuged at $20000 \mathrm{rpm}$ for one hour, to separate nanoparticles from aqueous medium.
The supernatant was taken and quantified by measuring at $260 \mathrm{~nm}$. The encapsulated drug was calculated using

$$
\begin{aligned}
& \text { Encapsulation efficiency }(\%) \\
& =\left(\frac{(\text { total amount of drug }- \text { amount of the free drug })}{\text { total drug }}\right) \\
& \quad \times 100, \\
& \text { Drug loading }(\%) \\
& =\left(\frac{(\text { amount of drug in nanoparticles })}{\text { total weight of nanoparticles }}\right) \times 100
\end{aligned}
$$

2.7. Fourier Transform Infrared Spectroscopy (FTIR). FTIR spectra of pure drug, Eudragit RS PO polymer, and nanoparticles were recorded using Perkin Elmer Spectrum 100 FTIR spectrophotometer, USA. The samples were placed onto sample holder and scanned in the spectral region between $4000 \mathrm{~cm}^{-1}$ and $650 \mathrm{~cm}^{-1}$.

2.8. Morphology. The morphology of the nanoparticles was studied using a scanning electron microscope, SEM (Field Emission Electron Microscope, JEOL JSM-7500F, Japan). The samples were prepared using a double adhesive tape stuck to an aluminium stub. Drops of nanoparticles dispersion were applied on the stub and dried overnight. They were then coated with gold under an argon atmosphere using a gold sputter in a high vacuum evaporator.

2.9. In Vitro Drug Release. The in vitro drug release studies were carried out using dialysis bag method [25]. Briefly, $20 \mathrm{mg}$ of freeze-dried samples was suspended in $10 \mathrm{~mL}$ of PBS ( $\mathrm{pH} 7.4$ and 1.5) and filled in dialysis bags with the molecular weight cut-off value of $12000 \mathrm{Da}$. The bags were placed separately in $50 \mathrm{~mL}$ PBS ( $\mathrm{pH} 7.4$ and 1.5), respectively, and agitated in a $37^{\circ} \mathrm{C}$ water bath shaker at $100 \mathrm{rpm}$. At predetermined time intervals, $5 \mathrm{~mL}$ aliquots were drawn and the dissolution media were then replaced by $5 \mathrm{~mL}$ of fresh PBS to maintain a constant volume. Concentration of drug 
TABLE 3: Observed responses in BBD for Eudragit RS PO nanoparticles.

\begin{tabular}{|c|c|c|c|c|c|c|c|}
\hline \multirow[b]{2}{*}{ Formulation code } & \multicolumn{3}{|c|}{ Variable levels in coded form } & \multicolumn{4}{|c|}{ Dependent variables } \\
\hline & $X_{1}$ & $X_{2}$ & $X_{3}$ & $\begin{array}{c}\text { PS } \\
(\mathrm{nm} \pm \mathrm{SD})\end{array}$ & $\begin{array}{c}\text { PDI } \\
( \pm \mathrm{SD}) \\
\end{array}$ & $\begin{array}{c}\mathrm{ZP} \\
(\mathrm{mv} \pm \mathrm{SD})\end{array}$ & $\mathrm{EE}(\%)$ \\
\hline 1 & -1 & -1 & 0 & $233.5 \pm 7.973$ & $0.107 \pm 0.019$ & $-35.2 \pm 4.47$ & 98 \\
\hline 2 & -1 & +1 & 0 & $307.65 \pm 4.59$ & $0.094 \pm 0.022$ & $-35.7 \pm 6.19$ & 99 \\
\hline 3 & +1 & -1 & 0 & $283.0 \pm 6.545$ & $0.131 \pm 0.021$ & $-32.2 \pm 9.19$ & 99 \\
\hline 4 & +1 & +1 & 0 & $404.5 \pm 6.382$ & $0.153 \pm 0.028$ & $-26.2 \pm 2.43$ & 99 \\
\hline 5 & -1 & 0 & -1 & $258.85 \pm 9.14$ & $0.109 \pm 0.018$ & $-36.5 \pm 4.14$ & 99 \\
\hline 6 & -1 & 0 & +1 & $260.5 \pm 9.589$ & $0.094 \pm 0.017$ & $-45.8 \pm 6.93$ & 99 \\
\hline 7 & +1 & 0 & -1 & $408.6 \pm 5.150$ & $0.132 \pm 0.056$ & $-19.9 \pm 2.62$ & 99 \\
\hline 8 & +1 & 0 & +1 & $317.1 \pm 8.567$ & $0.120 \pm 0.019$ & $-40.6 \pm 6.19$ & 99 \\
\hline 9 & 0 & -1 & -1 & $321.4 \pm 9.140$ & $0.108 \pm 0.018$ & $-39.8 \pm 4.14$ & 99 \\
\hline 10 & 0 & -1 & +1 & $305.95 \pm 3.87$ & $0.132 \pm 0.041$ & $-28.4 \pm 3.07$ & 99 \\
\hline 11 & 0 & +1 & -1 & $553.35 \pm 9.79$ & $0.104 \pm 0.027$ & $-25.6 \pm 1.32$ & 99 \\
\hline 12 & 0 & +1 & +1 & $301.4 \pm 13.51$ & $0.117 \pm 0.028$ & $-32.5 \pm 12.7$ & 99 \\
\hline 13 & 0 & 0 & 0 & $373.05 \pm 10.6$ & $0.123 \pm 0.077$ & $-37.5 \pm 0.97$ & 99 \\
\hline 14 & 0 & 0 & 0 & $329.65 \pm 5.36$ & $0.099 \pm 0.019$ & $-29.9 \pm 4.44$ & 99 \\
\hline 15 & 0 & 0 & 0 & $358.7 \pm 19.33$ & $0.124 \pm 0.030$ & $-36.0 \pm 12.3$ & 99 \\
\hline
\end{tabular}

released was determined using UV spectrophotometer. The percent drug release was determined by

$$
\text { Drug release }=\frac{\text { release drug }}{\text { total drug }} \times 100 \text {. }
$$

\section{Results and Discussion}

3.1. Solubility Study. Nanoprecipitation of hydrophobic drugs is more facile than the hydrophilic ones. Hydrophilic drugs tend to rapidly equilibrate from the organic to the outer aqueous phase leaving very little drug in the precipitating nanoparticles [26]. Modification of the traditional method with the use of surfactants improves the EE. Thus the purpose of solubility study was to identify suitable surfactant that possesses good solubilizing capacity for tenofovir to increase entrapment of the drug. A number of surfactants (SDS, PVA, Pluronic F127, and Poloxamer 188) were employed. It was found that the drug exhibited maximum solubility of $226 \mathrm{mg} \cdot \mathrm{mL}^{-1}$ in SDS, followed by Pluronic F127 (151 mg/mL) (Figure 1). It was also found that SDS was able to increase the drug solubility by threefold when compared to the solubility of tenofovir in water. Divya et al. [18] also determined the solubility of tenofovir in different oils and surfactants (Tween 20 and Tween 80 ) by employing the same method [18]. Their results indicated that the drug had a solubility of $33.3 \mathrm{mg} \cdot \mathrm{mL}^{-1}$ in Tween 20 , which is much less when compared to our results.

3.2. Preparation and Optimization of Nanoparticles. Threelevel, three-factor BBD was used to study the effect of variables in the preparation steps of nanoparticles. Modified nanoprecipitation method was used to prepare 15 formulations as per BBD. On the basis of the results obtained from solubility study, SDS was chosen as surfactant to stabilize

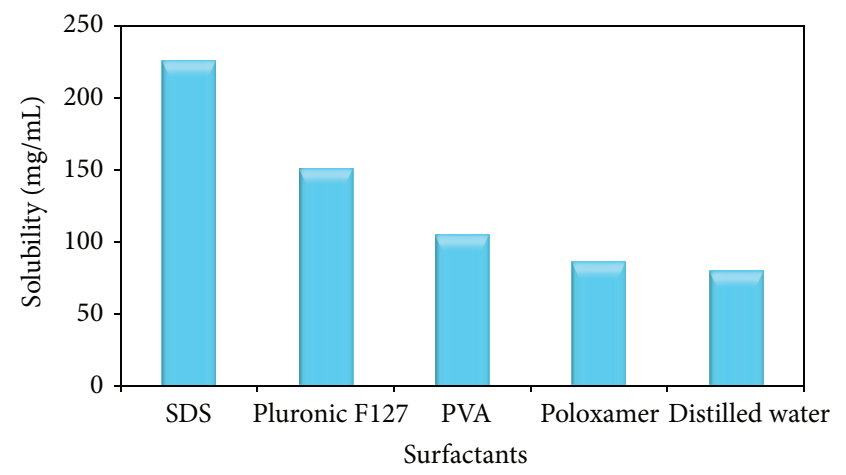

FIGURE 1: Solubility study of tenofovir in different surfactants.

nanoparticles and acetone was chosen as an organic phase. As shown in Table 3, the measured mean particle sizes are in the range of 233 to $499 \mathrm{~nm}$, PDI 0.094 to 0.153 , average zeta potential -19.9 to $-45.8 \mathrm{mv}$, and EE $98-99 \%$.

3.3. Statistical Analysis of the Model. ANOVA was performed to test the significance and adequacy of the model. The criteria followed in this model are if the calculated value of the $F$-ratio (signal to noise ratio) of the regression model is more than the standard value specified ( $f$-table) for $95 \%$ confidence level and the model is considered adequate within the confidence limit [27]. Normally the ratio greater than 4 is desirable for the model to be used effectively [28]. Factors with $p$ values that are less than 0.05 are considered to be statistically significant to the response [29]. Any terms in the models with high $f$-value and small $p$ value indicate more significant effect on the respective response variables. Moreover, coefficient of determination $\left(R^{2}\right)$ indicates the proportion of variation in the data that is explained by the 
TABLE 4: The result of ANOVA for mean particle size.

\begin{tabular}{lcccccc}
\hline Variables Coefficient & $t$-test & $p$ value & $R^{2}$ & $R^{2}$ adj. & $F$-test \\
\hline Constant & 351.778 & 70.589 & 0.000 & 0.9446 & 0.9152 & 32.191 \\
$X_{1}$ & 50.367 & 11.67 & 0.000 & & & \\
$X_{2}$ & 35.525 & 7.9997 & 0.000 & & & \\
$X_{3}$ & -15.475 & -3.5857 & 0.002 & & & \\
$X_{1} X_{3}$ & -23.275 & -3.1136 & 0.006 & & & \\
$X_{2} X_{3}$ & -38.35 & -5.1303 & 0.000 & & & \\
$X_{2} X_{2}$ & -20.1 & -2.6889 & 0.016 & & & \\
$X_{3} X_{3}$ & -29.171 & -4.9361 & 0.000 & & & \\
\hline
\end{tabular}

TABLE 5: The result ANOVA for EE.

\begin{tabular}{lcccccc}
\hline \multicolumn{2}{l}{ Variables Coefficient } & $t$-test & $p$ value & $R^{2}$ & $R^{2}$ adj. & $F$-test \\
\hline Constant & 99.0 & 216.748 & 0.000 & 0.9328 & 0.9126 & 46.254 \\
$X_{1}$ & -3.2667 & -6.3969 & 0.000 & & & \\
$X_{1}$ & -0.7333 & -1.436 & 0.166 & & & \\
$X_{1}$ & -0.8333 & -1.6319 & 0.118 & & & \\
$X_{1} X_{2}$ & -7.3 & -8.2533 & 0.000 & & & \\
$X_{1} X_{3}$ & -7.5 & -8.4794 & 0.000 & & & \\
$X_{1} X_{1}$ & -6.5667 & -9.5846 & 0.000 & & & \\
\hline
\end{tabular}

TABLE 6: ANOVA results for zeta potential.

\begin{tabular}{lcccccc}
\hline Variables & Coefficient & $t$-test & $p$ value & $R^{2}$ & $R^{2}$ adj. & $F$-test \\
\hline Constant & 34.98 & 39.156 & 0.000 & 0.8167 & 0.7352 & 10.023 \\
$X_{1}$ & -2.533 & -3.1841 & 0.005 & & & \\
$X_{2}$ & -1.1167 & -1.4305 & 0.177 & & & \\
$X_{3}$ & 2.1667 & 2.7233 & 0.014 & & & \\
$X_{1} X_{3}$ & 5.55 & 4.0275 & 0.001 & & & \\
$X_{2} X_{3}$ & 6.45 & 4.6806 & 0.036 & & & \\
$X_{1} X_{1}$ & -2.4133 & -2.2609 & 0.036 & & & \\
\hline
\end{tabular}

TABle 7: The result of ANOVA for PDI.

\begin{tabular}{lcccccc}
\hline Variables & Coefficient & $t$-test & $p$ value & $R^{2}$ & $R^{2}$ adj. & $F$-test \\
\hline Constant & 0.1163 & 57.983 & 0.000 & 0.654 & 0.59 & 10.396 \\
$X_{1}$ & 0.0183 & 6.0683 & 0.000 & & & \\
$X_{2}$ & 0.0011 & 0.3602 & 0.722 & & & \\
\hline
\end{tabular}

model. An $R^{2}$ closer to 1 or 0.9 indicates that the model fits the data perfectly. Tables 4-7 show results of the ANOVA model for mean particle size, EE, average zeta potential, and PDI, respectively.

The significant effects of the independents variables were graphically demonstrated by 3D surface plots. These kinds of plots are useful in studying the effects of two independent factors on the response at one time [30]. Since the model has more than two factors, one factor was held constant for each diagram [31]. The 3D surface plots illustrating the effects of independent variables on mean particle size, $\mathrm{EE}$, average zeta potential, and PDI are shown in Figures 2-5, respectively.

Mathematical models were developed to understand the nature of the true relationship between the input variables and the output variables of the system [32]. The equation is composed of linear and interaction terms. The linear terms are coded independent variables ranging between -1 and +1 [33] while interaction terms are second-order terms which are useful to estimate nonlinearity of response [34] and how response changes when two variables are simultaneously changed [8]. The negative sign for the coefficients in the equation indicates a negative effect on responses, while the positive sign indicates a positive effect [8]. The reduced mathematical models for mean particle size, $\mathrm{EE}$, average zeta potential, and PDI are presented by (4) to (7), respectively.

3.4. Effect of Independent Variables on Particle Size. The results presented in ANOVA Table 4 indicate that all the studied factors $\left(X_{1}=\right.$ ratio of polymer to a drug, $X_{2}=$ concentration of surfactant, and $X_{3}=$ sonication time) were found to have significant effect on mean particle size. The coefficient of determination $\left(R^{2}\right)$ of the model for mean particle size was 0.9446 with adjusted $R^{2}$ of 0.9152 indicating that $94.46 \%$ and $91.52 \%$ of the model can be predicted. The equation derived for mean particle size is given in

$$
\begin{aligned}
\text { Mean particle size }= & 351.778+50.369 X_{1}+35.525 X_{2} \\
& -15.475 X_{3}-23.275 X_{1} X_{3} \\
& -38.35 X_{2} X_{3}-20.1 X_{2}^{2} \\
& -29.171 X_{3}^{2}
\end{aligned}
$$

where $X_{1}, X_{2}$, and $X_{3}$ are ratio of a polymer to a drug, concentration of a surfactant, and sonication time, respectively, and $X_{1} X_{3}$ and $X_{2} X_{3}$ are interaction effects between ratio of a polymer to a drug and sonication time, concentration of a surfactant, and sonication time while $X_{1}^{1}$ and $X_{3}^{2}$ are quadratic effect on mean particle size.

From equation, it was observed that ratio of a polymer and concentration of a surfactant had positive effect on mean particle size whereas sonication time had negative effect. Figure 2 provides the $3 \mathrm{D}$ response surface plots showing the change of particles size corresponding to the change of independent variables. Figure 2(a) shows the effect of ratio of a polymer to a drug and concentration of a surfactant at a constant sonication time. It can be seen from the plot that an increase in ratio of a polymer and concentration of a surfactant resulted in an increased mean particle size. It was explained that an increase in polymer concentration leads to an increase in viscous force resisting droplet breakdown by sonication [35]. Small mean particle size was obtained by low polymer to a drug having ratio of $1: 1$ (50 $\mathrm{mg}$ of a polymer to $50 \mathrm{mg}$ of a drug). These results are in good agreement with the results reported by Gannu et al. [36] where they showed that smaller particle size was observed with the formulation having drug polymer ration $1: 1$ due to the surfactant concentration enough to maintain the stability of the particles [36]. Small mean particle size was observed in Figure 2(b) when sonication time was increased. This may be due to the increase erosion effect on the surface of large particle and particle agglomerates resulting in small particles [37]. 


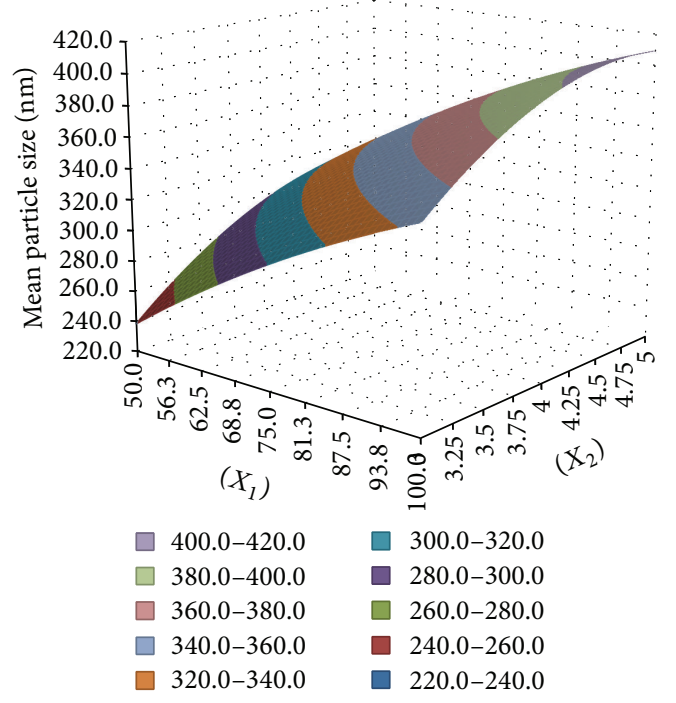

$X_{1}=$ ratio of a polymer to a drug

$X_{2}=$ concentration of a surfactant

(a)

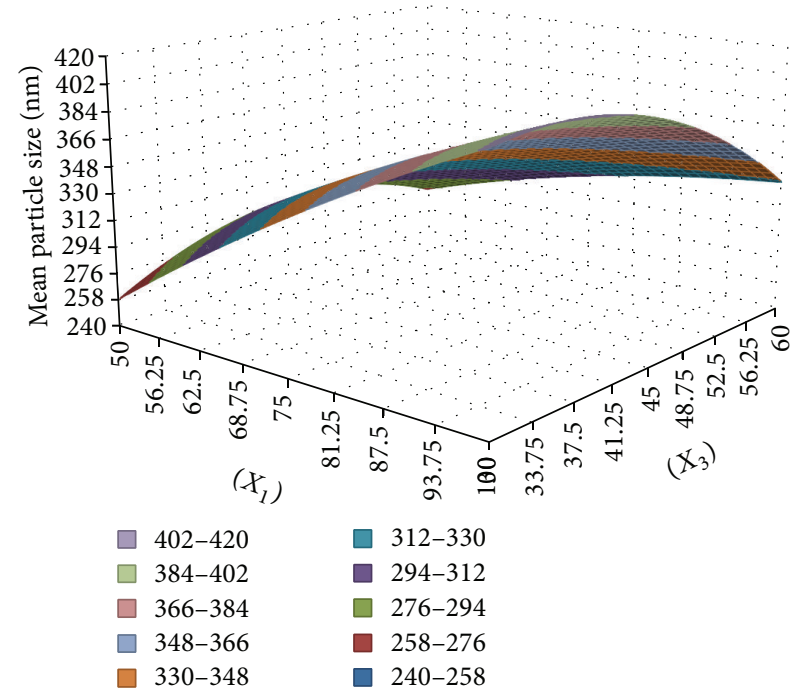

$X_{1}=$ ratio of a polymer to a drug

$X_{3}=$ sonication time

(b)

FIGURE 2: 3D response surface plots showing the effect of (a) ratio of a polymer to a drug $\left(X_{1}\right)$ and concentration of a surfactant $\left(X_{2}\right)$ at constant sonication time $\left(X_{3}\right)$ and (b) ratio of a polymer to a drug $\left(X_{1}\right)$ and sonication time $\left(X_{3}\right)$ at constant concentration of a surfactant $\left(X_{2}\right)$.

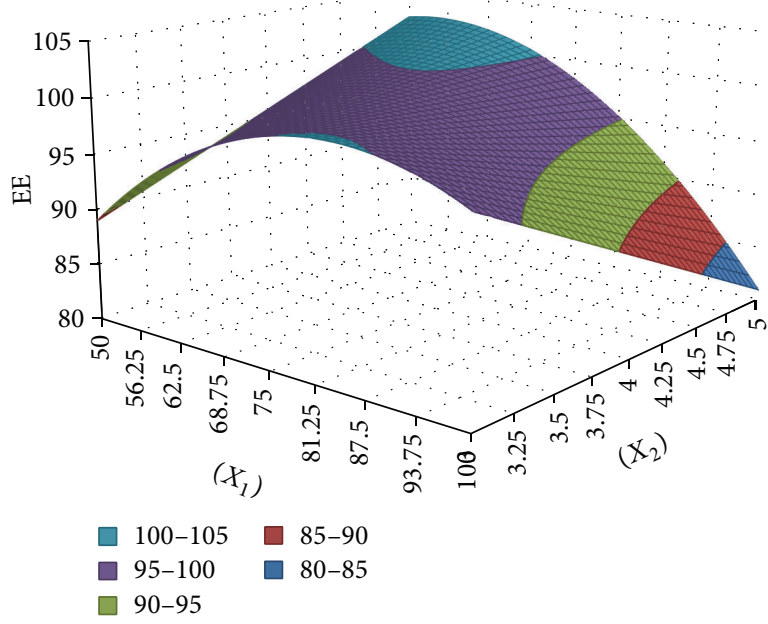

$X_{1}=$ ratio of a polymer to a drug

$X_{2}=$ concentration of a surfactant

(a)

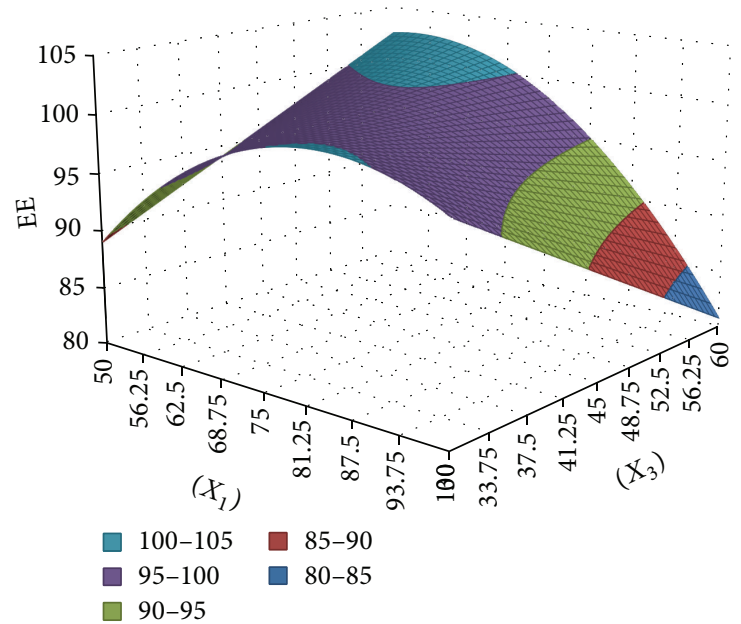

$X_{1}=$ ratio of a polymer to a drug

$X_{3}=$ sonication time

(b)

Figure 3: 3D response surface plots showing the effect of (a) ratio of a polymer to a drug $\left(X_{1}\right)$ and concentration of a surfactant $\left(X_{2}\right)$ at constant sonication time $\left(X_{3}\right)$ and (b) ratio of a polymer to a drug $\left(X_{1}\right)$ and sonication time $\left(X_{3}\right)$ at constant concentration of a surfactant $\left(X_{2}\right)$.

3.5. Effect of Independent Variables on EE. Table 5 provides ANOVA results for EE. It was observed that ratio of a polymer to a drug $\left(X_{1}\right)$ has significant effect whereas other factors do not have an effect on EE. The interactions between ratio of a polymer to a drug and concentration of a surfactant and ratio of a polymer to a drug and sonication time were also statistically significant $(p<0.05)$ on EE. The reduced model for EE is presented in

$$
\begin{aligned}
\mathrm{EE}= & 99.0-3.2667 X_{1}-0.7333 X_{2}-0.8333 X_{3} \\
& -7.38 X_{1} X_{2}-7.5 X_{1} X_{3}-6.5667 X_{1}^{1},
\end{aligned}
$$




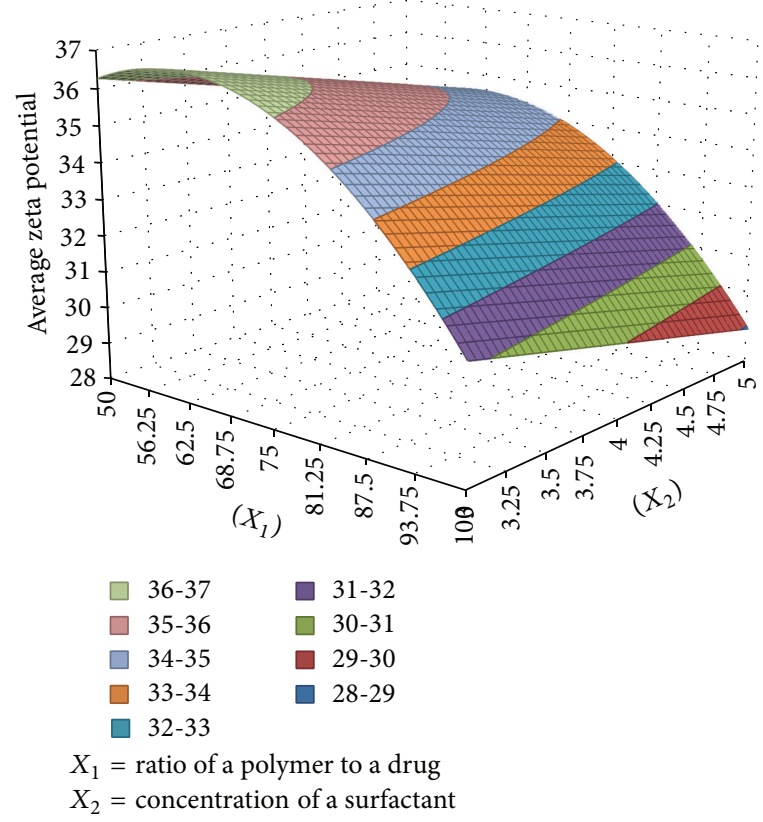

(a)

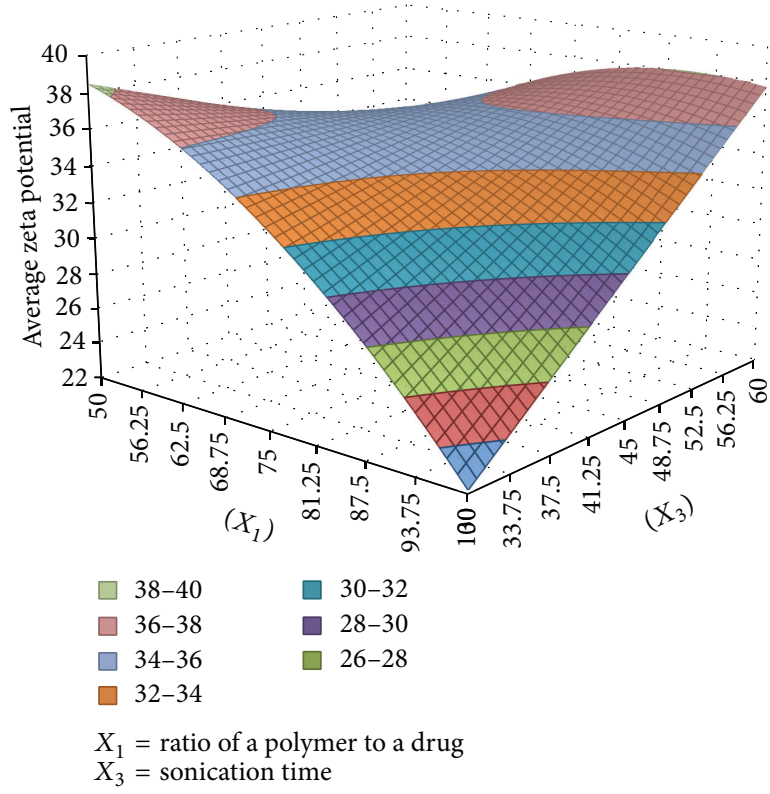

(b)

FIGURE 4: 3D response surface plots showing the effect of (a) ratio of a polymer to a drug $\left(X_{1}\right)$ and concentration of a surfactant $\left(X_{2}\right)$ at constant sonication time $\left(X_{3}\right)$ and (b) ratio of a polymer to a drug $\left(X_{1}\right)$ and sonication time $\left(X_{3}\right)$ at constant concentration of a surfactant $\left(X_{2}\right)$.

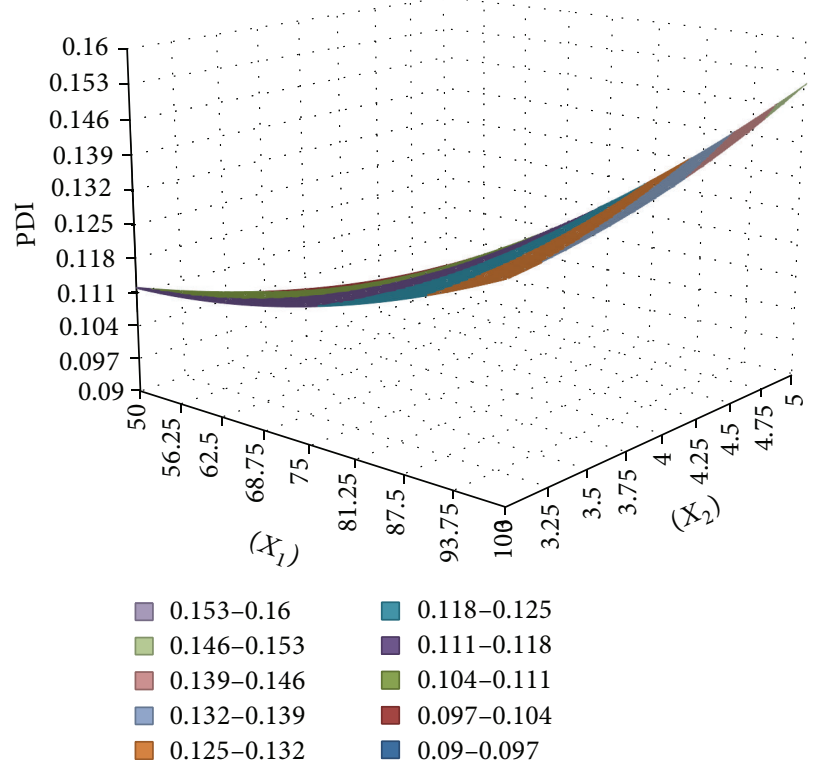

$X_{1}=$ ratio of a polymer to a drug $X_{2}=$ concentration of a surfactant

(a)

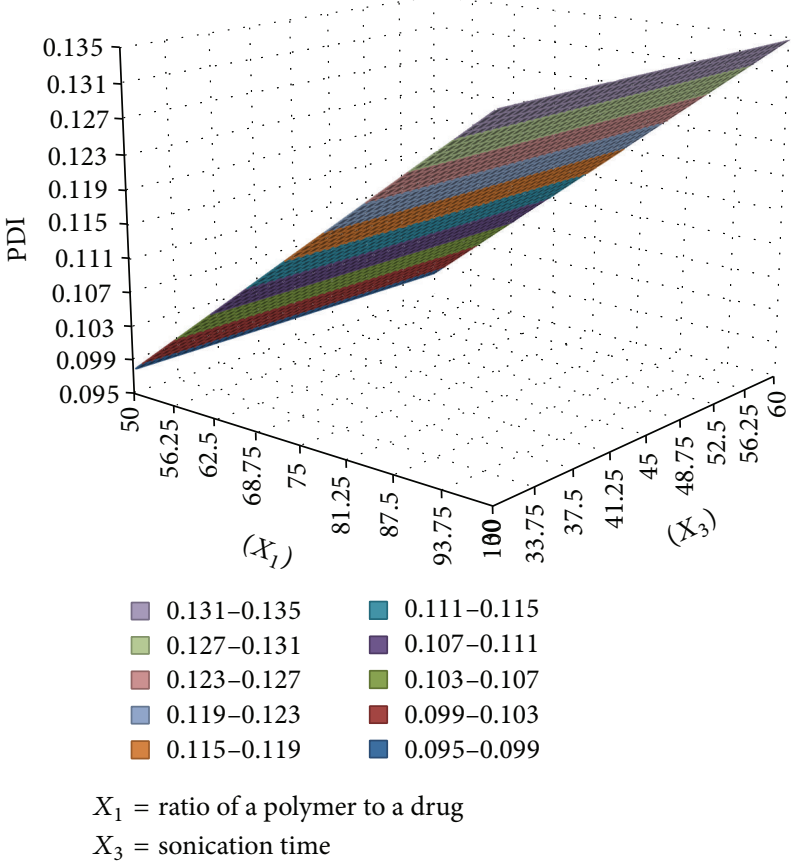

(b)

FIGURE 5: 3D response surface plots showing the effect of (a) ratio of a polymer to a drug $\left(X_{1}\right)$ and concentration of a surfactant $\left(X_{2}\right)$ at constant sonication time $\left(X_{3}\right)$ and (b) ratio of a polymer to a drug $\left(X_{1}\right)$ and sonication time $\left(X_{3}\right)$ at constant concentration of a surfactant $\left(X_{2}\right)$. 
where $X_{1}, X_{2}$, and $X_{3}$ are ratio of a polymer to a drug, concentration of a surfactant, and sonication time, respectively, and $X_{1} X_{2}$ and $X_{1} X_{3}$ are interaction effects between ratio of a polymer to a drug and sonication time while $X_{1}^{1}$ is quadratic effect on EE.

The direction of the magnitude of significance as shown in (5) was negative for ratio of a polymer to a drug indicating an inverse relationship between ratio of a polymer to a drug and $\mathrm{EE}$. This can further be seen from 3D surface plots in Figure 3. From Figure 3(a), a higher EE was attained with decrease in ratio of polymer to a drug and a maximum concentration of a surfactant at a constant sonication time. Similarly in Figure 3(b), a higher EE was obtained with a decrease in ratio of a polymer to a drug and a maximum sonication time at a constant concentration of a surfactant. This can be due to the fact that an increase in polymer concentration led to an enhancement of the concentration gradient between emulsion droplets and the continuous phase, as a result increasing the amount of drug partitioning into the continuous phase [38].

3.6. Effect of Independent Variables on Zeta Potential. Table 6 shows that zeta potential is significantly influenced by ratio of a polymer to a drug and sonication time. It was also found that the interaction between ratio of a polymer and sonication time and concentration of surfactant and sonication time significantly influence zeta potential. The coefficient of determination $(0.8167)$ for the response was found to be close with adj. $R^{2}(0.7352)$, indicating that the model has predicted the response values well. The quadratic model of zeta potential is shown in

$$
\begin{aligned}
& \text { Average zeta potential } \\
& \qquad \begin{array}{l}
=34.98-2.5333 X_{1}-1.1167 X_{2}+2.1667 X_{3} \\
\quad+5.55 X_{1} X_{3}+6.45 X_{2} X_{3}-2.4133 X_{1}^{1},
\end{array}
\end{aligned}
$$

where $X_{1}, X_{2}$, and $X_{3}$ represent ratio of a polymer to a drug, concentration of a surfactant, and sonication time, respectively, and $X_{1} X_{3}$ and $X_{2} X_{3}$ are interaction effects between ratio of a polymer to a drug and sonication time and concentration of a surfactant and sonication time while $X_{1}^{1}$ are quadratic effect.

3D surface plots corresponding to zeta potential are illustrated in Figure 4. From Figure 4(a), it was observed that decreasing the ratio of a polymer to a drug from $100 \mathrm{mg}$ to $50 \mathrm{mg}$ resulted in an increased zeta potential with an increased concentration of a surfactant. The results are similar to the results published by various researchers [22] that the zeta potential decreases at high level of ratio of a polymer to a drug. The reduction in zeta potential is attributed to the effect of the shift in the plane of shear away from the particle surface [39]. Figure 5(b) also shows that a decrease in ratio of a polymer resulted in an increased zeta potential with an increased sonication time.

3.7. Effect of Independent Variables on PDI. In case of PDI, ratio of polymer to a drug has shown statistically significant
TABLE 8: Predicted and observed values for the model.

\begin{tabular}{lccc}
\hline $\begin{array}{l}\text { Dependent } \\
\text { variable }\end{array}$ & Predicted & Observed & $\begin{array}{c}\text { Percentage } \\
\text { prediction error }\end{array}$ \\
\hline PS $\left(Y_{1}\right)$ & 240.3 & 233.5 & -2.83 \\
PDI $\left(Y_{2}\right)$ & 0.108 & 0.107 & -0.93 \\
EE $\left(Y_{3}\right)$ & 99 & 98 & -1.01 \\
Zeta & -34.6 & -35.2 & 1.73 \\
potential $\left(Y_{4}\right)$ & & & \\
\hline
\end{tabular}

influence $(p<0.05)$ on PDI as shown in Table 7. All other tested factors and their interaction did not have an effect on PDI. The reduced model for PDI is presented in

$$
\mathrm{PDI}=0.1163+0.0183 X_{1}+0.0011 X_{2}
$$

where $X_{1}$ and $X_{2}$ are ratio of a polymer to a drug and concentration of a surfactant, respectively. Figure 4 shows $3 \mathrm{D}$ response surface plots showing the change of PDI corresponding to the change of independent variables. As shown in Figure 4(a) increasing an amount of polymer resulted in an increase in PDI. The same profile was observed in Figure 3(b). The equation explaining the effect of independent factors on PDI is shown in (7) below.

3.8. Validation of the Model. The aim of the optimization was to obtain small particles size, small PDI, high EE, and high zeta potential. The optimal formulation was found to be $50 \mathrm{mg}$ of polymer, $3 \%$ concentration of surfactant (SDS), and 45 minutes of sonication time. In order to confirm the predicted results, the predicted and experimental results were compared as shown in Table 8 . The percentage prediction error was calculated which helps in the validation of generated regression by using (8). The percentage errors between measured and predicted values were found to be insignificant. A graphical representation of an optimized mean particle size is given in Figure 6:

$$
\begin{aligned}
& \text { Percentage prediction error } \\
& =\frac{\text { Observed }- \text { Predicted }}{\text { Predicted }} \times 100 \text {. }
\end{aligned}
$$

3.9. FTIR and SEM Analysis of Optimized Nanoparticles. The FTIR spectra of tenofovir, Eudragit RS PO, and Eudragit RS PO-tenofovir nanoparticles are shown in Figure 7. FTIR spectra of pure tenofovir drug showed a weak intensity broad band at $3225 \mathrm{~cm}^{-1}$ corresponding to $\mathrm{O}-\mathrm{H}$ of aromatic ring, a sharp peak at $1600 \mathrm{~cm}^{-1}$ which is due to phosphoric $\mathrm{P}=\mathrm{O}$ group and $\mathrm{N}-\mathrm{H}$ wagging bands at 660 and $900 \mathrm{~cm}^{-1}$ [40]. Eudragit spectra showed peaks at 1260,1736 , and $1340 \mathrm{~cm}^{-1}$ which are due to $\mathrm{C}-\mathrm{O}, \mathrm{C}=\mathrm{O}$, and $\mathrm{C}-\mathrm{N}$, respectively. A stronger, wide peak was observed in the final nanoparticles without major shift in the structure of Eudragit. This could be attributed to an ionic electrostatic interaction between the drug and the polymer during formation of nanoparticles. Additionally, there was compatibility between drug and the polymer, meaning that, during the process of formulation, 


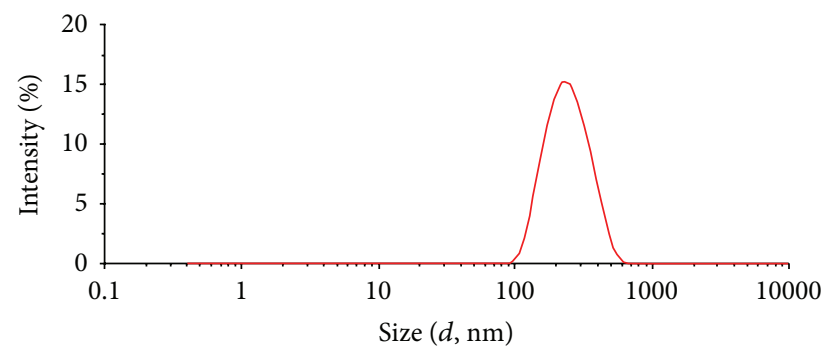

FIGURE 6: Mean particle size of optimized nanoparticles.

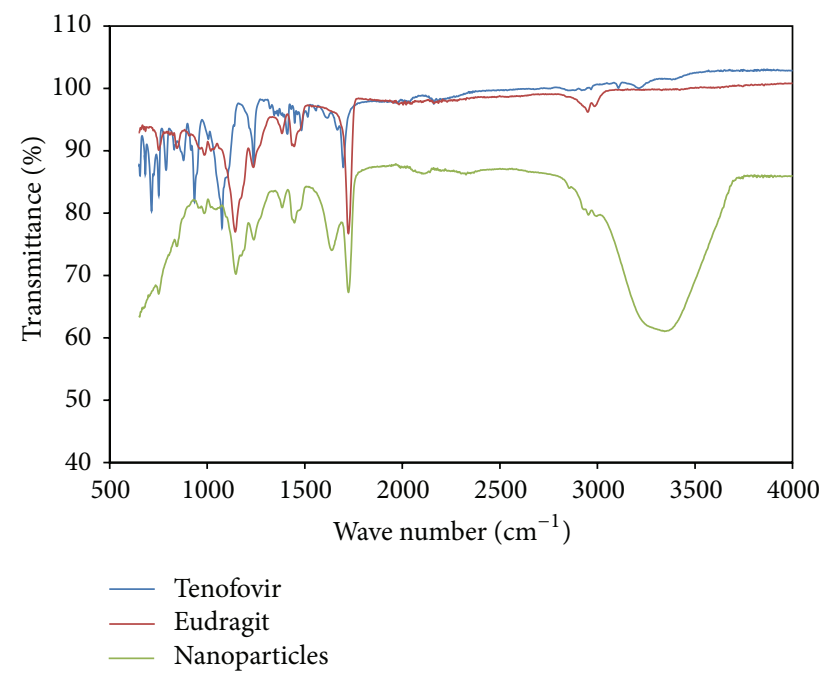

FIGURE 7: FTIR spectra of tenofovir, Eudragit RS PO, and Eudragit RS PO-tenofovir nanoparticles.

polymer has not reacted with the drug to give rise to reactant products; it is only physical mixture. A spherical morphology of the prepared nanoparticles was observed in the SEM images (Figure 8).

3.10. In Vitro Drug Release Studies. The in vitro drug release studies were carried out in dissolution media $\mathrm{pH}$ (7.4 and 1.5) within a period of one week. The release profiles for both pH 7.4 and 1.5 are displayed in Figure 9. An identical release profiles were observed in both dissolution media, which is due to the fact that Eudragit RS PO is $\mathrm{pH}$ independent; the release of drug is dependent on the diffusion of the drug from the matrix of the polymer. After 80 hours about $90 \%$ of the drug was able to be released in both media. However, the release of a drug in acidic media $\mathrm{pH} 1.5$ was slightly higher than that of the alkaline media; this is attributed to the fact that Eudragit RS PO contains quaternary ammonium groups and solubilisation of these quaternary ammonium groups in acidic $\mathrm{pH}$ leads to formation of pores in the matrix, thereby releasing more drug in the acidic $\mathrm{pH}$ [41]. Long term release of the drug may be due to the charge interactions between the cationic polymer and anionic drug resulting in a gradual drug release. These results demonstrated that the nanoparticles were able to sustain the release of tenofovir

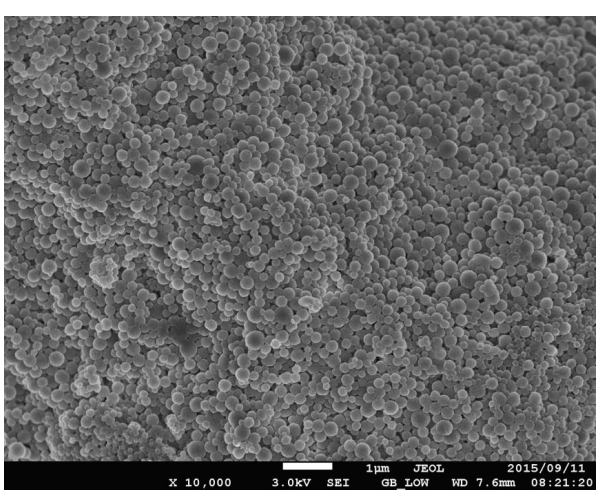

FIgURE 8: Scanning electron microscope image of Eudragit RS POtenofovir nanoparticles.

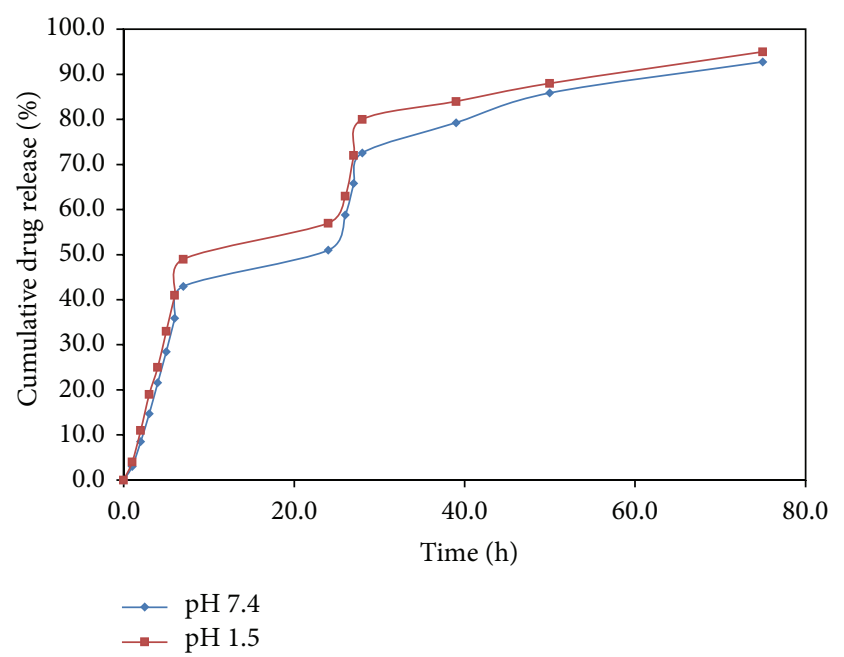

FIGURE 9: The release curves of tenofovir from nanoparticles in various $\mathrm{pH}$ (7.4 and 1.5).

by showing slow absorption rate and therefore were more suitable for controlling the release of the drug.

\section{Conclusion}

The encapsulation of tenofovir in Eudragit RS PO nanoparticles was successful with the aid of an optimal design based on BBD. The characteristics of the designed nanoparticles are attractive for pharmaceutical use as they showed high EE, physical stability, narrow size distribution, and prolonged drug release.

\section{Conflict of Interests}

The authors declare that there is no conflict of interests regarding the publication of this paper.

\section{References}

[1] J. Meng, T. F. Sturgis, and B.-B. C. Youan, "Engineering tenofovir loaded chitosan nanoparticles to maximize microbicide 
mucoadhesion," European Journal of Pharmaceutical Sciences, vol. 44, no. 1-2, pp. 57-67, 2011.

[2] S. Tokar, "Tenofovir, leading HIV medication, linked with risk of kidney damage," February 2012, https://www.ucsf.edu/news/ 2012/02/11508/tenofovir-leading-hiv-medication-linked-riskkidney-damage.

[3] T. M. Viread, Tenofovir Disoproxile Fumarate, Gilead Sciences, Foster City, Calif, USA, 2009.

[4] A. Pozniak, "Tenofovir: what have over 1 million years of patient experience taught us?” International Journal of Clinical Practice, vol. 62, no. 8, pp. 1285-1293, 2008.

[5] L. Tshweu, L. Katata, L. Kalombo, and H. Swai, "Nanoencapsulation of water-soluble drug, lamivudine, using a double emulsion spray-drying technique for improving HIV treatment," Journal of Nanoparticle Research, vol. 15, article 2040, 2013.

[6] L. Katata, L. Tshweu, S. Naidoo, L. Kalombo, and H. Swai, "Design and formulation of nano-sized spray dried efavirenzpart I: influence of formulation parameters," Journal of Nanoparticle Research, vol. 14, no. 11, article 1247, 2012.

[7] S. Mitragotri, P. A. Burke, and R. Langer, "Overcoming the challenges in administering biopharmaceuticals: formulation and delivery strategies," Nature Reviews Drug Discovery, vol. 13, no. 9, pp. 655-672, 2014.

[8] H. M. Ibrahim, H. R. Ismail, and A. E. A. Lila, "Formulation and optimization of ocular poly-D, L-lactic acid nano drug delivery system of amphotericin-B using box behnken design," International Journal of Pharmacy and Pharmaceutical Sciences, vol. 4, no. 2, pp. 342-349, 2012.

[9] M. H. Abdallah, O. A. Sammour, H. A. El-Ghamry, H. M. ElNahas, and W. Barakat, "Development and characterization of controlled release ketoprofen microspheres," Journal of Applied Pharmaceutical Science, vol. 2, no. 3, pp. 60-67, 2012.

[10] R. Kola and B. P. Kumar, "A detailed description of synthetic and natural polymers which are used in the formulation of sustained release drug delivery system: a review," Journal of Chemical and Pharmaceutical Sciences, vol. 6, no. 3, pp. 161-169, 2013.

[11] K. Animesh, M. Afrasim, R. R. Bommareddy, A. Ayaz, R. Shruthi, and H. G. Shivakumar, "Applicability and approaches of (Meth) acrylate copolymers (Eudragits) in novel drug delivery systems," Current Drug Therapy, vol. 7, no. 4, pp. 219-234, 2012.

[12] F. Hoobakht, F. Ganji, E. Vasheghani-Farahani, and S. M. Mousavi, "Eudragit RS PO nanoparticles for sustained release of pyridostigmine bromide," Journal of Nanoparticle Research, vol. 15, article 1912, 2013.

[13] T. Zhang, C. Zhang, V. Agrahari, J. B. Murowchick, N. A. Oyler, and B.-B. C. Youan, "Spray drying tenofovir loaded mucoadhesive and $\mathrm{pH}$-sensitive microspheres intended for HIV prevention," Antiviral Research, vol. 97, no. 3, pp. 334-346, 2013.

[14] S. Arora, S. Gupta, R. K. Narang, and R. D. Budhiraja, "Amoxicillin loaded chitosan-alginate polyelectrolyte complex nanoparticles as mucopenetrating delivery system for H. pylori," Scientia Pharmaceutica, vol. 79, no. 3, pp. 673-694, 2011.

[15] D. C. Montgomery, Design and Analysis of Experiments, WileyInterscience, Montréal, Canada, 5th edition, 2001.

[16] G. E. P. Box and J. S. Hunter, Statistics for Experimenters, John Wiley \& Sons, New York, NY, USA, 1978.

[17] S. Schubert, J. T. Delaney Jr., and U. S. Schubert, "Nanoprecipitation and nanoformulation of polymers: from history to powerful possibilities beyond poly(lactic acid)," Soft Matter, vol. 7, no. 5, pp. 1581-1588, 2011.
[18] C. E. Mora-Huertas, H. Fessi, and A. Elaissari, "Polymerbased nanocapsules for drug delivery," International Journal of Pharmaceutics, vol. 385, no. 1-2, pp. 113-142, 2010.

[19] A. Divya, P. Kumar, K. Gnanaprakash, and M. Gobinath, "Design, formulation and characterization of tenofovir microemulsion as oral drug delivery," International Journal of Pharmacy Review \& Research, vol. 4, pp. 1-5, 2014.

[20] L. Jenita, J. Josephine, C. Vijaya, B. Wilson, B. K. Savitha, and R. Suma, "Design and characterization of bovine serum albumin nanocarriers for tenofovir by modified desolvation method," Journal of Pharmacy Research, vol. 5, no. 9, pp. 4663-4667, 2012.

[21] U. Bilati, E. Allémann, and E. Doelker, "Nanoprecipitation versus emulsion-based techniques for the encapsulation of proteins into biodegradable nanoparticles and process-related stability issues," AAPS PharmSciTech, vol. 6, no. 4, pp. E594E604, 2005.

[22] L. Julianna and R. T. Eniko, "Nanomedicine applications towards the cure of HIV," Nanomedicine: Nanotechnology, Biology, and Medicine, vol. 9, no. 1, pp. 28-38, 2013.

[23] D. Alukda, T. Sturgis, and B.-B. C. Youan, "Formulation of tenofovir-loaded functionalized solid lipid nanoparticles intended for HIV prevention," Journal of Pharmaceutical Sciences, vol. 100, no. 8, pp. 3345-3356, 2011.

[24] S. H. Syed, S. U. Premnath, and K. Muddu, "Development and validaton of stability indicating RP-HPLC method for tenofovoir nanoparticle formulation," International Journal of Pharmacy and Pharmaceutical Sciences, vol. 5, no. 2, pp. 245248, 2013.

[25] A. S. Zidan, C. Spinks, J. Fortunak, M. Habib, and M. A. Khan, "Near-infrared investigations of novel anti-HIV tenofovir liposomes," The AAPS Journal, vol. 12, no. 2, pp. 202-214, 2010.

[26] P. Sharma and S. Garg, "Pure drug and polymer based nanotechnologies for the improved solubility, stability, bioavailability and targeting of anti-HIV drugs," Advanced Drug Delivery Reviews, vol. 62, no. 4-5, pp. 491-502, 2010.

[27] T. Zhang, T. F. Sturgis, and B.-B. C. Youan, " $\mathrm{pH}$-responsive nanoparticles releasing tenofovir intended for the prevention of HIV transmission," European Journal of Pharmaceutics and Biopharmaceutics, vol. 79, no. 3, pp. 526-536, 2011.

[28] T. J. Johnson, K. M. Gupta, J. Fabian, T. H. Albright, and P. F. Kiser, "Segmented polyurethane intravaginal rings for the sustained combined delivery of antiretroviral agents dapivirine and tenofovir," European Journal of Pharmaceutical Sciences, vol. 39, no. 4, pp. 203-212, 2010.

[29] D. S. Singare, S. Marella, K. Gowthamrajan, G. T. Kulkarni, R. Vooturi, and P. S. Rao, "Optimization of formulation and process variable of nanosuspension: an industrial perspective," International Journal of Pharmaceutics, vol. 402, no. 1-2, pp. 213220, 2010.

[30] S. H. Shah, M. J. Shan, and J. R. Sharma, "An overview on brain targeting drug delivery system," Pharmaceutical Reviews, vol. 7, no. $1,2009$.

[31] M. Chidambaram and K. Krishnasamy, "Modifications to the conventional nanoprecipitation technique: an approach to fabricate narrow sized polymeric nanoparticles," Advanced Pharmaceutical Bulletin, vol. 4, no. 2, pp. 205-208, 2014.

[32] Q. Y. Tan, N. Wang, H. Yang et al., "Characterization, stabilization and activity of uricase loaded in lipid vesicles," International Journal of Pharmaceutics, vol. 384, no. 1-2, pp. 165-172, 2010.

[33] M. Alauddin, M. A. Mazid, M. A. El Baradi, and M. S. J. Hashmi, "Cutting forces in the end milling of Inconel 718," Journal of 
Materials Processing Technology, vol. 300, no. 3-4, pp. 153-159, 1998.

[34] M. Manohar, J. Jomy, T. Selvaraj, and D. Sivakumar, "Application of Box Behnken design to optimize the parameters for turning Inconel 718 using coated carbide tools," International Journal of Scientific and Engineering Research, vol. 4, no. 4, pp. 2229-5518, 2013.

[35] W.-L. Guo, Y.-B. Zhang, J.-H. Lu et al., "Optimization of fermentation medium for nisin production from Lactococcus lactis subsp. lactis using response surface methodology (RSM) combined with artificial neural network-genetic algorithm (ANN-GA)," African Journal of Biotechnology, vol. 9, no. 38, pp. 6264-6272, 2010.

[36] R. Gannu, V. V. Yamsani, S. K. Yamsani, C. R. Palem, and M. R. Yamsani, "Optimization of hydrogels for transdermal delivery of lisinopril by box-behnken statistical design," AAPS PharmSciTech, vol. 10, no. 2, pp. 505-514, 2009.

[37] R. Ragonese, M. Macka, J. Hughes, and P. Petocz, "The use of the Box-Behnken experimental design in the optimisation and robustness testing of a capillary electrophoresis method for the analysis of ethambutol hydrochloride in a pharmaceutical formulation," Journal of Pharmaceutical and Biomedical Analysis, vol. 27, no. 6, pp. 995-1007, 2002.

[38] J. P. Maran, S. Manikandan, B. Priya, and P. Gurumoorthi, "Box-Behnken design based multi-response analysis and optimization of supercritical carbon dioxide extraction of bioactive flavonoid compounds from tea (Camellia sinensis L.) leaves," Journal of Food Science and Technology, vol. 52, no. 1, pp. 92104, 2015.

[39] M. A. Tekindal, H. Bayrak, B. Ozkaya, and Y. Genc, "Boxbehnken experimental design in factorial experiments: the importance of bread for nutrition and health running head," Turkish Journal of Field Crops, vol. 17, no. 2, pp. 115-123, 2012.

[40] M. S. Gambhire, M. R. Bhalekar, and V. M. Gambhire, "Simvastatin loaded Solid lipid nanoparticles: formulation optimization using Box Behnken design, characterization and in vitro evaluation," Current Pharma Research, vol. 1, pp. 157-164, 2011.

[41] N. T. Anh, N. T. Chi, T. K. Tran et al., "Preparation and characterization of ketoprofen loaded eudragit RS polymeric nanoparticles for controlled release," Advances in Natural Sciences: Nanoscience and Nanotechnology, vol. 3, no. 4, Article ID 045015, 2012. 

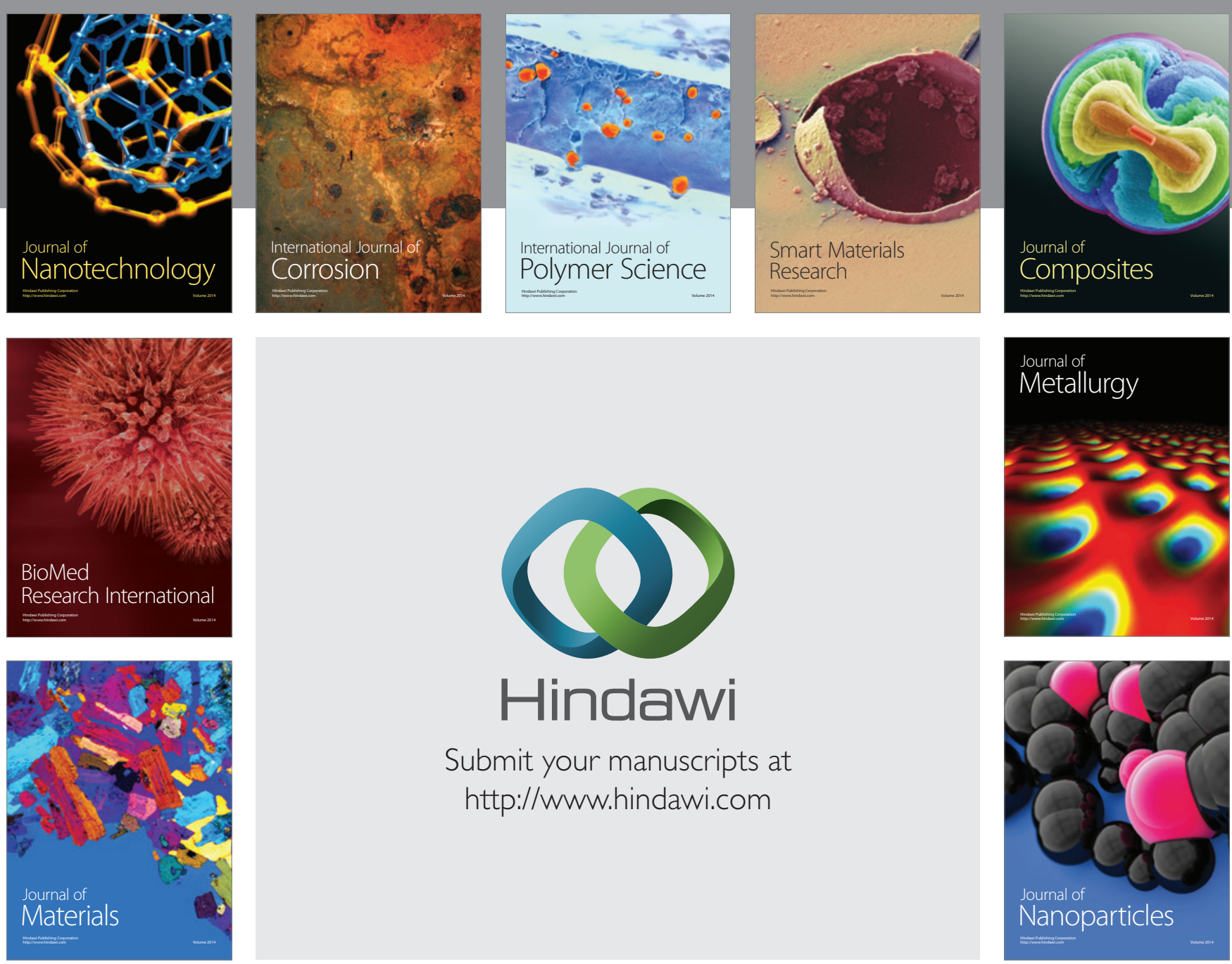

Submit your manuscripts at http://www.hindawi.com
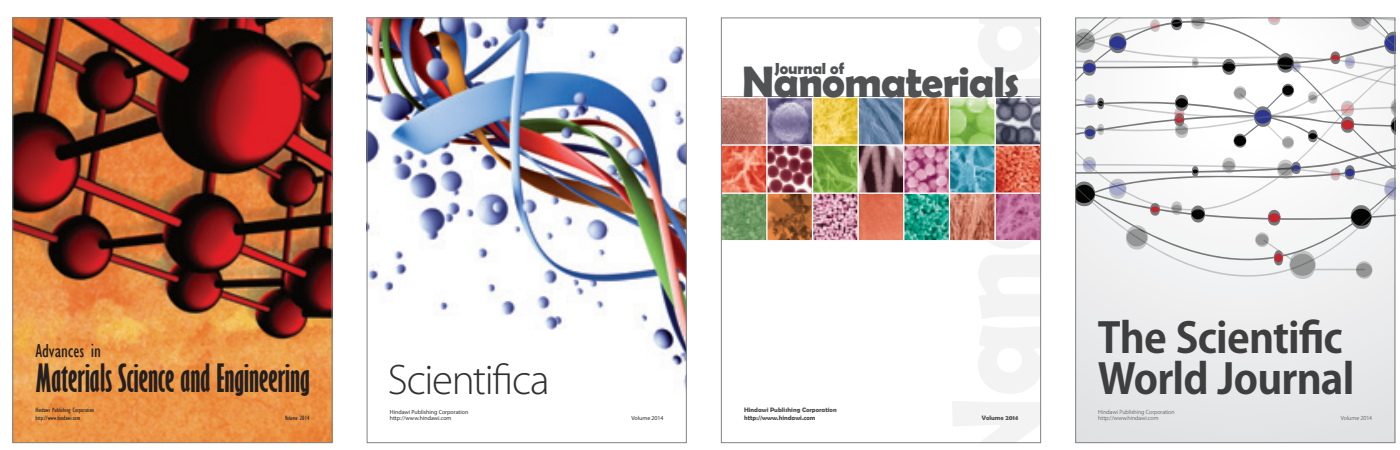

\section{The Scientific World Journal}
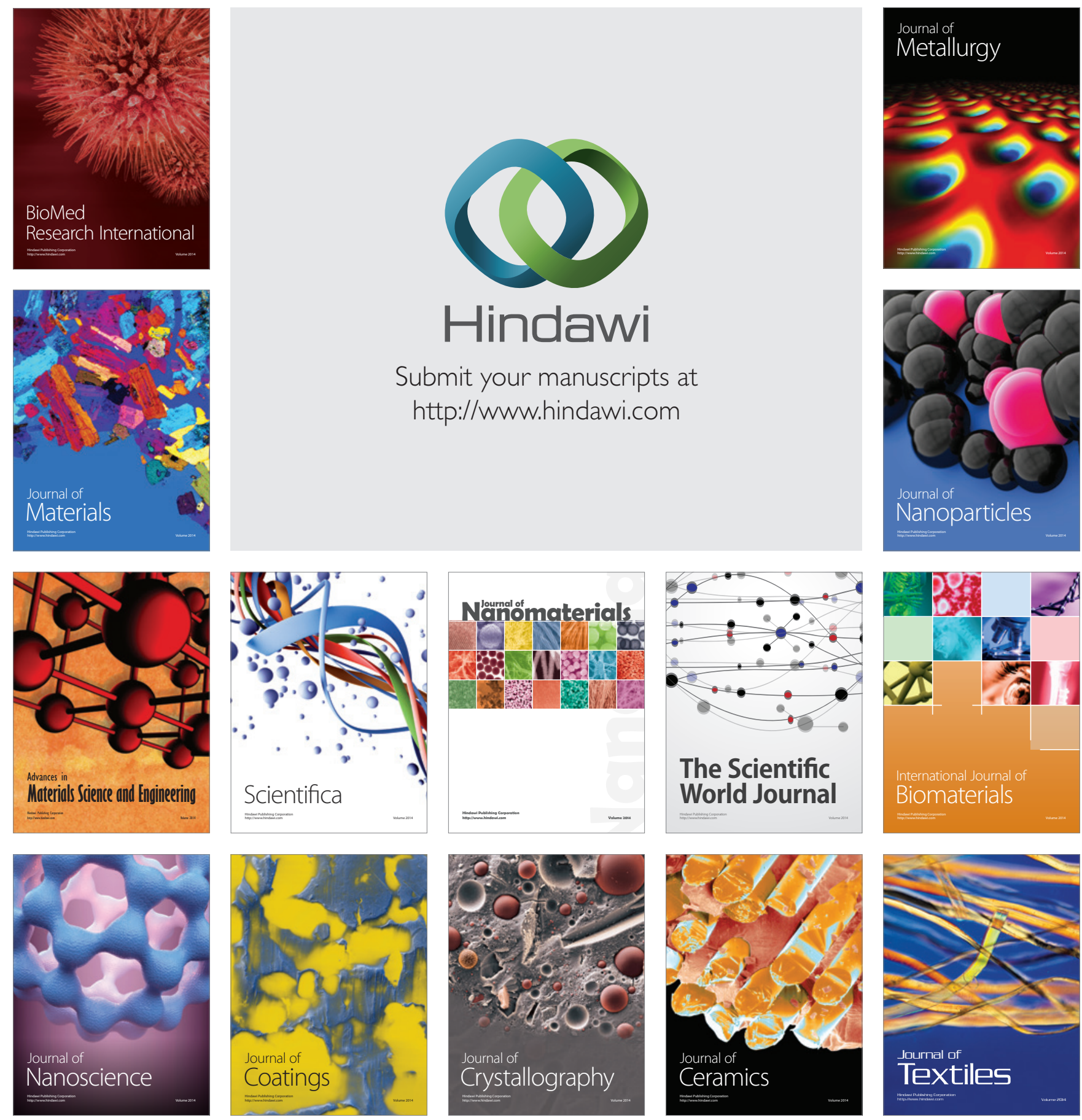